\title{
Extending the Shelf Life of Fresh Marula (Sclerocarya birrea) Juice by Altering Its Physico-Chemical Parameters
}

\author{
S. Dube ${ }^{1}$, N.R. Dlamini ${ }^{2}$, I. Shereni ${ }^{1}$ and T. Sibanda ${ }^{1}$ \\ ${ }^{1}$ Department of Applied Biology and Biochemistry, \\ National University of Science and Technology, Ascot, Bulawayo, \\ ${ }^{2}$ CSIR Biosciences, Pretoria \\ 1Zimbabwe \\ ${ }^{2}$ South Africa
}

\section{Introduction}

\subsection{Taxonomy and distribution}

Sclerocarya birrea (A. Rich.) Hochst. subsp. caffra (Sond.) (marula) is a very common and widespread throughout much of sub-Saharan Africa and is a member of the Anacardiaceae family, along with 650 species and 70 genera of mainly tropical or subtropical evergreen or deciduous trees, shrubs and woody vines along side with the mango (Mangifera indica L.). S. birrea has three recognised subspecies; fruit-bearing species of which Sclerocarya birrea subsp. caffra is the most ubiquitous and occurs in east tropical Africa (Kenya, Tanzania), south tropical Africa (Angola, Malawi, Mozambique, Zambia and Zimbabwe) and southern Africa (Botswana, Namibia, South Africa and Swaziland) as well as Madagascar. Sclerocarya birrea subsp. multifoliolata (Engl.) Kokwaro subspecies occurs in mixed deciduous woodland and wooded grassland in Tanzania. The tree grows in a wide variety of soils but prefers welldrained soil. It exists at altitudes varying from sea level to $1800 \mathrm{~m}$ and an annual rainfall range of $200-1500 \mathrm{~mm}$. The key factor limiting its distribution is its sensitivity to frost (Von, 1983; Palgrave, 1990; Mizrahi and Nerd, 1996; Aganga and Mosase, 2001; Emanuel, et al., 2005).

\subsection{Flowering and fruiting}

S. birrea is a dioecious species. Male and female flowers occur separately, but not always, on separate trees. The flowers are small, with red sepals and yellow petals, and are borne in 50 - 80 mm-long sprays of small oblong clusters (Venter and Venter, 1996; van Wyk and van Wyk, 1997; van Wyk et al., 2002).

\subsection{Traditional uses of marula fruit}

It has many uses, including the fruits that are eaten fresh or after fermentation to make a beer, the kernels are eaten or the oil extracted, the leaves are browsed by animals and have 
medicinal properties, as does the bark. The wood is carved into traditional utensils such as spoons and plates as well as decorative curios. Because of the widespread occurrence and use of $S$. birrea it has frequently been identified as a key species in the development of rural businesses using the fruit, beer, nuts or oil and therefore a good candidate for domestication (Fox and Norwood, 1982; Nerd and Mizrahi, 1993; Mizrahi and Nerd, 1996; Shackleton et al., 2002). The fruit and nuts have extensive commercial value. The fruit is described as having an exotic flavor and high nutritive value (for example, vitamin $C$ content is up to 3 times higher in 'marula' fruit than equivalent weight of oranges. The fruit is often fermented to give an alcoholic beverage. Some tribes, such as the Pedi, prepare a relish from the leaves of S. birrea. The Zulu people of South Africa regard S. birrea fruit as a potent insecticide (van Wyk, et al., 2002; Mdluli, 2005). The whole fruit is used in many parts of southern Africa for brewing beer and distilling spirits. In Mozambique, South Africa and Zambia, the fruit of $S$. birrea is used to flavor liqueur. The gum obtained from the tree is rich in tannins, and hence, it is employed in the production of an ink substitute. Zimbabwean and South African villagers benefit from the customary usage of $S$. birrea wood in the manufacture of dishes, maize stamping mortars, drums, toys, curios, divining bowls and carvings. The peel from $S$. birrea fruit is of paramount importance in the production of oil for cosmetic purposes (Ojewole, et al., 2010).

\subsection{The marula fruit}

Female trees bear pale-yellow, round fruit with thick leather-like rind, and fibrous, juicy, mucilaginous flesh. The fruit, which is about the size of a golf ball, is pale-yellow when ripe, with a diameter of $30-40 \mathrm{~mm}$ (Nerd and Mizrahi, 1993; Ojewole et al., 2010). The fruit has sour taste, and is much sought-after by birds, game mammals and humans, because of its delicious pulp, and edible, tasty nuts (van Wyk, et al., 2002). The fruit pulp contains citric acid, vitamin $C$ and sugar, while the nut is rich in non-drying oil and protein (van Wyk, et al., 2002; Hillman, et al., 2008; Ojewole, et al., 2010). The only way to make this fruit juice available to children before fermentation and is by finding ways to extend its shelf life. The average Sclerocarya birrea (marula) tree under the climatic conditions of Matebeleland South produces $20000 \pm 5000$ fruits per season. The fruits ripen between February and April. The time from ripening onset to rotting of the fruit was $16 \pm 4$ days. Skin colour starts to change on day 3 after abscission, and a completely yellow colour is obtained by day 12 .

\subsection{Fruit ripening}

Marula fruits abscise before ripening; at this stage the skin color is green and the fruit is firm. The time for fruit abscission varies among trees. Of the studied trees, fruits abscised mainly in March and in late April. This can be attributed to genetic variation, which can be exploited for expanding the harvest period by planting clones that ripen at different times. (Palgrave, 1990; Mdluli, 2005; Dlamini and Dube, 2008).

\section{Marula pulp characteristics}

Of the wide range of nutrients in the Marula pulp the Vitamin C content has attracted the most attention. Indeed the vitamin $C$ content is important to local communities who know well that it prevents scurvy. The fruit has small amounts of other vitamins such as thiamine, riboflavin and nicotinic acid. It is $85 \%$ moisture and $14 \%$ carbohydrate, mostly sucrose. 
Citric acid is the most abundant acid excluding ascorbic acid, but malic and tartaric acid have also been noted. The mineral composition of the fruit shows high concentrations of Potassium, Calcium and Magnesium (Shackleton, et al., 2010). The aroma of Marula is perceived by other people to be like that of the grapefruit and there are in fact compounds that the two fruits have in common. However, the similarity in taste between grapefruit and marula is probably because of a dominant bitter taste caused by non volatiles. Others have likened the smell of marula juice to pineapples but this is probably also only in part due to complimentary volatile components such as ethyl acetate, benzaldehyde, linalool. With a unique and pleasurable taste, an attractive colour and odour and health properties such as high vitamin $C$ and potassium, this fruit has all the physical requirements of the growing it for industrial purposes. Marula, Scelerocarya birrea, subspecies caffera, is one of Africa's botanical treasures. The flesh of the fruit clings onto to its brown stone. The flesh is very fibrous and juicy. Inside the woody stone are two to three seeds, which are very rich in oil and protein. (Shackleton, et al., 2010).

Generally edible fruits constitute a commercially important and nutritionally indispensable food commodity. Being a part of a balanced diet, fruits play a vital role in human nutrition by supplying the necessary growth regulating factors essential for maintaining normal health. Fruits are widely distributed in nature. One of the limiting factors that influence their economic value is the relatively short ripening period and reduced post-harvest life. Fruit ripening is a highly coordinated, genetically programmed, and an irreversible phenomenon involving a series of physiological, biochemical, and organoleptic changes, that finally leads to the development of a soft edible ripe fruit with desirable quality attributes. Excessive textural softening during ripening leads to adverse effects/spoilage upon storage. Carbohydrates play a major role in the ripening process, by way of depolymerization leading to decreased molecular size with concomitant increase in the levels of ripening inducing specific enzymes, whose target differ from fruit to fruit. (Hillman, et al 2008; Brumell and Harpster, 2001; Prasanna, et al., 2007; Prescott, 2011) The major classes of cell wall polysaccharides that undergo modifications during ripening are starch, pectins, cellulose, and hemicelluloses. Pectins are the common and major components of primary cell wall and middle lamella, contributing to the texture and quality of fruits. Their degradation during ripening seems to be responsible for tissue softening of a number of fruits. Structurally pectins are a diverse group of heteropolysaccharides containing partially methylated D-galacturonic acid residues with side chain appendages of several neutral polysaccharides. The degree of polymerization/esterification and the proportion of neutral sugar residues/side chains are the principal factors contributing to their (micro-) heterogeneity. Pectin degrading enzymes such as polygalacturonase, pectin methyl esterase, lyase, and rhamnogalacturonase are the most implicated in fruit-tissue softening. Recent advances in molecular biology have provided a better understanding of the biochemistry of fruit ripening as well as providing a hand for genetic manipulation of the entire ripening process. It is desirable that significant breakthroughs in such related areas will come forth in the near future, leading to considerable societal benefits(Brumell and Harpster, 2001; Prasanna, et al., 2007; Prescott, 2011).

Excessive softening is the main factor limiting fruit shelf life and storage. Transgenic plants modified in the expression of cell wall modifying proteins have been used to investigate the role of particular activities in fruit softening during ripening, and in the manufacture of processed fruit products. Transgenic experiments show that polygalacturonase (PG) activity 
is largely responsible for pectin depolymerization and solubilization, but that PG-mediated pectin depolymerization requires pectin to be de-methyl-esterified by pectin methylesterase (PME), and that the PG beta-subunit protein plays a role in limiting pectin solubilization. Suppression of PG activity only slightly reduces fruit softening (but extends fruit shelf life), suppression of PME activity does not affect firmness during normal ripening, and suppression of beta-subunit protein accumulation increases softening. All these pectinmodifying proteins affect the integrity of the middle lamella, which controls cell-to-cell adhesion and thus influences fruit texture (Arthachinta, 2000; Brumell and Harpster, 2001; Prasanna, et al., 2007; Prescott, 2011). Diminished accumulation of either PG or PME activity considerably increases the viscosity of tomato juice or paste, which is correlated with reduced polyuronide depolymerization during processing. In contrast, suppression of betagalactosidase activity early in ripening significantly reduces fruit softening, suggesting that the removal of pectic galactan side-chains is an important factor in the cell wall changes leading to ripening-related firmness loss. (Brumell and Harpster, 2001; Prasanna, et al., 2007; Prescott, 2011). Suppression or over expression of endo-(1--4) beta-D-glucanase activity has no detectable effect on fruit softening or the depolymerization of matrix glycans, and neither the substrate nor the function for this enzyme has been determined. The role of xyloglucan endotransglycosylase activity in softening is also obscure, and the activity responsible for xyloglucan depolymerization during ripening, a major contributor to softening, has not yet been identified. However, ripening-related expansion protein abundance is directly correlated with fruit softening and has additional indirect effects on pectin depolymerization, showing that this protein is intimately involved in the softening process. (Brumell and Harpster, 2001; Prasanna, et al., 2007; Prescott, 2011). Transgenic work has shown that the cell wall changes leading to fruit softening and textural changes are complex, and involve the coordinated and interdependent activities of a range of cell wall-modifying proteins. It is suggested that the cell wall changes caused early in ripening by the activities of some enzymes, notably beta-galactosidase and ripening-related expansin, may restrict or control the activities of other ripening-related enzymes necessary for the fruit softening process (Brumell and Harpster, 2001; Prasanna et al., 2007; Prescott, 2011). Whether the sugar of fruits is formed within them, or introduced through the stem, and, if formed in the fruits, from what substance formed, are questions which have been investigated, but not wholly settled. It has been pretty generally held that starch in the unripe fruits is converted into sugar in the ripe fruits; the fruit acids inducing the change, as we know they have power to do. But starch is not found in the unripe stage of all fruits, and, in the cases where found, its quantity is sometimes too small to serve as the source of all the sugar of the ripened fruit The maturity of fruit is the period of its maximum quantity of sugar. Sooner or later, the quantity of sugar begins to diminish, and then the fruit is overripe. It is safe to say that the sugar often begins to decompose during the life of the fruit; that is to say, fruit becomes overripe during its life. It would be difficult, however, to fix on the termination of the life of fruit. We certainly cannot say that life ceases when the circulation with the plant is cut off; and we cannot say that life continues in the sarcocarp until it is wholly disintegrated. (Brumell and Harpster, 2001; Prasanna, et al., 2007; Prescott, 2011). Now it is within the limits of our subject to inquire by what changes the sugar begins to disappear. In general terms, sugar suffers oxidation in ripe fruits, small portions being oxidized away even during the production of larger portions, and before perfect maturity. We do not know what fruit constituents, if any, result in this oxidation. The final products of oxidation, carbonic acid and water, are exhaled during ripening, and with greater rapidity after maturity has been 
passed. The quantity of acids in fruits usually diminishes during ripening. The diminution is not, however, nearly so great as it appears to the taste, because the acid of ripe fruits is masked to the taste by the larger proportions of sugar and the pectous substances then present. The removal of acids is chiefly due to oxidation. It is not found that acids are neutralized, to any considerable extent, during ripening, by alkalies conveyed through the stem (Brumell and Harpster, 2001; Prasanna et al., 2007; Prescott, 2011). It is stated that the acids continue to oxidize away, after the sugar has reached its maximum and before it begins to diminish. Hence, perfect ripeness in fruit has been defined as that period during the maximum quantity of sugar when the quantity of acid is least. This will be, of course, just before the sugar begins to diminish. It has been stated that both citric and malic acids are often found in unripe grapes, and are substituted by tartaric acid during the ripening. Oxalic acid is more often found in unripe than in ripe fruits. It is to be desired that closer determinations should be made as to the presence and proportion of oxalic acid in tomatoes and some other fruits (Brumell and Harpster, 2001; Prasanna et al., 2007; Prescott, 2011).

\section{Fresh marula fruit juice shelf life extension by high-pressure processing - pascalization and aseptic methods}

The application of high hydrostatic pressure in processing of food is of great interest because of its ability to inactivate food related microorganisms and enzymes, at low temperature, without the need for chemical preservatives. High hydrostatic pressures, around $650 \mathrm{MPa}$ reduces the microbial load in foods such as fruits. Pressure-treated foods have organoleptic properties similar to fresh products, which is a major advantage in juice processing as it matches consumer demand for healthy, nutritious and "natural" products. However, an important issue arises when we consider the acceptance of such products by the consumer (Jay, 1986; Adams and Moss, 1995; Deliza et al., 2004). It is also noted that the microbicidal activity of high pressure is enhanced by low $\mathrm{pH}$ or temperatures above and below ambient. High hydrostatic pressure acts primarily on non-covalent linkages, such as ionic bonds, hydrogen bonds and hydrophobic interactions, and it promotes reactions in which there is an overall decrease in volume (Adams and Moss, 1995; Indrawati et al., 2008; Sampedro et al., 2008; Chao, et al 2011). It can have profound effects on proteins, where such interactions are critical to structure and function, although the effect is variable and depends on individual protein structure. Other proteins are relatively unaffected and this can cause problems when they have enzymic activity which limits product shelf-life. Pectin esterase in orange juice, for instance, must be inactivated to stabilize the desired product cloudiness, but is very stable to pressures up to $1000 \mathrm{MPa}$. Non-protein macromolecules can also be affected by high pressures so that pascalized starch products often taste sweeter due to conformational changes in the starch which allow salivary amylase greater access. Adverse effects on protein structure and activity obviously contribute to the antimicrobial effect of high pressures, although the cell membrane also appears to be an important target. Membrane lipid bilayers have been shown to compress under pressure and this alters their permeability. As a general rule vegetative bacteria and fungi can be reduced by at least one log cycle by $400 \mathrm{MPa}$ applied for $5 \mathrm{~min}$. (Indrawati et al., 2008; Sampedro et al., 2008; Chao et al., 2011)

Bacterial endospores are more resistant to hydrostatic pressure, tolerating pressures as high as $1200 \mathrm{MPa}$. Their susceptibility can be increased considerably by modest increases in temperature, when quite low pressures $(100 \mathrm{MPa})$ can produce spore germination, a process 
in which the spores lose their resistance to heat and to elevated pressure. Hydrostatic processing has a number of appealing features for the food preparations such as Marula fruit juice. (Indrawati, et al., 2008; Sampedro, et al., 2008; Chao, et al., 2011)

It acts instantly and uniformly throughout a substance so that the processing time is not related to container size and there is none of the penetration problems associated with heat processing. Nutritional quality, flavour, appearance and texture resemble the fresh material very closely. To the consumer where it has been used it is regarded as a 'natural' process with none of the negative associations of processes such as irradiation or chemical preservatives. ((Indrawati, et al., 2008; Sampedro, et al., 2008; Chao, et al., 2011)

Appertized foods include those which are hermetically sealed into containers, usually cans, and then subjected to heat process in-pack. While this has been hugely successful as a long term method of food preservation, it does require extended heating periods in which a food's functional and chemical properties can be adversely affected. (Adams and Moss, 1995)

\subsection{Fresh marula fruit juice shelf life extension by temperature control}

Low-temperature storage - chilling and freezing the rates of most chemical reactions are temperature dependent; as the temperature is lowered so the rate decreases. Since food spoilage is usually a result of chemical reactions mediated by microbial and endogenous enzymes, the useful life of many foods can be increased by storage at low temperatures. Chilled foods are those foods stored at temperatures near, but above their freezing point, typically $0-5^{\circ} \mathrm{C}$. Chill storage can change both the nature of spoilage and the rate at which it occurs. There may be qualitative changes in spoilage characteristics as low temperatures exert a selective effect preventing the growth of mesophiles and leading to a microflora dominated by psychrotrophs (Paine and Paine, 1992; Blakestone, 1999; Cheikh, et al., 2009; Philip, 2010).

Blanching is achieved either by brief immersion of foods into hot water or the use of steam. Its primary functions are as follows: inactivation of enzymes that might cause undesirable changes during freezing storage, enhancement or fixing of the green color of certain vegetables, reduction in the numbers of microorganisms on the foods, facilitating the packing of leafy vegetables by inducing wilting, displacement of entrapped air in the plant tissues. When water is used, it is important that bacterial spores not be allowed to build up sufficiently to contaminate the juice. Reductions of initial microbial loads as high as $99 \%$ have been claimed upon blanching (Blakestone, 1999; Cheikh, et al., 2009; Philip 2010).

According to Adams and Moss,1995 the term Pasteurization is given to heat processes typically in the range $60-80{ }^{\circ} \mathrm{C}$ and applied for up to a few minutes, is used for two purposes. First is the elimination of a specific pathogen or pathogens associated with a product. This type of pasteurization is often a legal requirement introduced as a public health measure when a product has been frequently implicated as a vehicle of illness. The second reason for pasteurizing a product is to eliminate a large proportion of potential spoilage organisms, thus extending its shelf-life. This is normally the objective when acidic products such as beers, fruit juices, pickles, and sauces are pasteurized. Where pasteurization is introduced to improve safety, its effect can be doubly beneficial (Adams and Moss, 1995; Blakestone, 1999; Cheikh, et al., 2009; Philip, 2010). The process cannot 
discriminate between the target pathogen(s) and other organisms with similar heat sensitivity so a pasteurization which destroys say Salmonella will also improve shelf-life. The converse does not normally apply since products pasteurized to improve keeping quality are often intrinsically safe due to other factors such as low $\mathrm{pH}$. On its own, the contribution of pasteurization to extension of shelf-life can be quite small; particularly if the pasteurized food lacks other contributing preservative factors such as low $\mathrm{pH}$, where as appertization refers to processes where the only organisms that survive processing are non-pathogenic and incapable of developing within the product under normal conditions of storage. As a result, appertized products have a long shelf-life even when stored at ambient temperatures. An appertized or commercially sterile food is not necessarily sterile - completely free from viable organisms (Adams and Moss, 1995; Blakestone, 1999; Cheikh, et al., 2009; Philip, 2010).

Sterilization: This is the process of destroying all forms of microbial life. A sterile object is free from living organism. killing bacteria is the irreversible loss of the bacteria's ability to reproduce. The cells are killed over a period of time at a constant exponential rate that is the inverse of exponential growth rate. Some portion of population dies during any given time. The graph of logarithm of number of survivor's $\mathrm{v} / \mathrm{s}$ time in hours shows that the death rate is constant. Slope of this curve is a measure of death-rate (Jay, 1986; Adams and Moss, 1995). The probability of killing the organisms is also proportional to concentration of chemical agent or intensity of physical agent. It takes time to kill the population and if we have many cells, we must treat them for a longer time. Although imperfect, cooking and canning are the most common applications of heat sterilization. Boiling water kills the vegetative stage of all common microbes. Cooking food does not sterilize food but simply reduces the number of disease-causing micro-organisms to a level that is not dangerous for people with normal digestive and immune systems. Pressure cooking is analogous to autoclaving and when performed correctly renders food sterile. (Jay, 1986; Adams and Moss, 1995).

In UHT processing the food is heat processed before it is packed and then sealed into sterilized containers in a sterile environment. This approach allows more rapid heating of the product, the use of higher temperatures than those employed in canning, typically 130$140^{\circ} \mathrm{C}$, and processing times of seconds rather than minutes (Jay, 1986; Adams and Moss, 1995; Michael and Hepell 2000).The advantage of using higher temperatures is that the $z$ value for chemical reactions such as vitamin loss, browning reactions and enzyme inactivation is typically $25-40^{\circ} \mathrm{C}$ compared with $10^{\circ} \mathrm{C}$ for spore inactivation. This means that they are less temperature sensitive so that higher temperatures will increase the microbial death rate more than they increase the loss of food quality associated with thermal reactions. A common packing system used in conjunction with UHT processing is a form/ fill/seal operation in which the container is formed in the packaging machine from a reel of plastic or laminate material, although some systems use preformed containers. In order to obtain commercial sterility it is given a bactericidal treatment, usually with hydrogen peroxide, sometimes coupled with UV irradiation (Jay, 1986; Adams and Moss, 1995).

\subsection{Fresh marula fruit juice shelf life extension by chemical methods}

Chemicals that can possibly be used for sterilization marula juice include the gases ethylene oxide, Ozone, hydrogen peroxide which are examples of chemical sterilization techniques based on oxidative capabilities. 
Ethylene oxide (ETO) is the most commonly used form of chemical sterilization. Due to its low boiling point of $10.4^{\circ} \mathrm{C}$ at atmospheric pressure, Ethylene oxide behaves as a gas at room temperature. Ethylene oxide chemically reacts with amino acids, proteins, and DNA to prevent microbial reproduction. The sterilization process is carried out in a specialized gas chamber. After sterilization, products are transferred to an aeration cell, where they remain until the gas disperses and the product is safe to handle. Ethylene oxide is used for cellulose and plastics irradiation, usually in hermetically sealed packages. Ethylene oxide can be used with a wide range of plastics and other materials without affecting their integrity. Ethylene oxide vapours are inflammable so a mixture of ethylene oxide 10 to $20 \%$ with 80 to $90 \%$ $\mathrm{CO}_{2}$, or Feron is used, $\mathrm{CO}_{2}$ or Feron serve as inert diluent which prevent inflammability. It is a unique and powerful sterilizing agent. Bacterial spores show little resistance to destruction by this agent. (Morga, et al., 1979; Adams and Moss, 1995) It has got very good penetrating power. It passes through the sterilizes large packets of materials and even certain plastics. It should be used with caution. The concentration of ethylene oxide and temperature and humidity are critical factors which determine the time required for sterilization. The apparatus used for its application is an autoclave modified. It is effective at low temperature and does not damage the material exposed to it but it is slow in action. The mode of action is believed to be alkylation reactions with organic compounds such enzymes and other proteins. (Jay, 1986; Adams and Moss, 1995). Ozone sterilization has been recently approved for use in the U.S. It uses oxygen that is subjected to an intense electrical field that separates oxygen molecules into atomic oxygen, which then combines with other oxygen molecules to form ozone. Ozone is used as a disinfectant for water and food. It is used in both gas and liquid forms as an antimicrobial agent in the treatment, storage and processing of foods (Adams and Moss, 1995; Cullen et al., 2010; Philip, 2010).

Low Temperature Gas Plasma (LTGP) is used as an alternative to ethylene oxide. It uses a small amount of liquid hydrogen peroxide $\left(\mathrm{H}_{2} \mathrm{O}_{2}\right)$, which is energized with radio frequency waves into gas plasma. This leads to the generation of free radicals and other chemical species, which destroy organisms (Jay, 1986; Adams and Moss, 1995).

Hypochlorites: Calcium hypochlorite $\mathrm{Ca}(\mathrm{OCl})_{2}$ and sodium hypochlorite $\mathrm{NaOCl}$ are widely used. They are in powder or liquid forms and in various concentrations from $5-70 \% . \mathrm{CaCl}_{2}$ is used to sanitize equipment and $1 \% \mathrm{NaOCl}$ for personal hygiene and household disinfection. (Adams and Moss, 1995; Cullen et al., 2010; Philip, 2010). This could find application in the extension of marula juice shelf life extension.

\subsection{Preservatives}

Although some would regard all chemical additions to food as synonymous with adulteration, many are recognized as useful and are allowed. Additives may be used to aid processing, to modify a food's texture, flavour, nutritional quality or colour but, here, we are concerned with those which primarily effect keeping quality: preservatives(Jay, 1986). Preservatives are defined as 'substances capable of inhibiting, retarding or arresting the growth of micro-organisms or of any deterioration resulting from their presence or of masking the evidence of any such deterioration'. They do not therefore include substances which act by inhibiting a chemical reaction which can limit shelf-life, such as the control of rancidity or oxidative discoloration by antioxidants. Neither does it include a number of food additives which are used primarily for other purposes. Preservatives may be 
microbicidal and kill the target organisms or they may be microbistatic in which case they simply prevent them growing. This is very often a dose-dependent feature; higher levels of antimicrobial proving lethal while the lower concentrations that are generally permitted in foods tend to be microbistatic (Jay, 1986). For this reason chemical preservatives are useful only in controlling low levels of contamination and are not a substitute for good hygiene practices, effect on flavour and on product $\mathrm{pH}$, thus potentiating their own action by increasing the proportion of undissociated acid present.

Benzoic acid occurs naturally in cherry bark, cranberries, greengage plums, tea and anise but is prepared synthetically for food use. Its antimicrobial activity is principally in the undissociated form and since it is a relatively strong acid ( $\mathrm{pH} 4.19)$ it is effective only in acid foods. As a consequence, its practical use is to inhibit the growth of spoilage yeasts and moulds (Jay, 1986).

\subsection{Fresh marula fruit juice shelf life extension by radiation methods}

Gamma rays and X-rays which have ionizing energy enough to pull electrons away from molecules and ionize them. When such radiation passes through cells it creates free hydrogen and hydroxyl radical and some peroxides which in turn can cause different kinds of intracellular damage. U.V. light does not ionize; it is absorbed quite specifically by different chemical species that can engage in a variety of chemical reactions not possible for unexcited molecules. Organisms may be subjected to acoustic radiation (sound waves). Ionizing radiation is also used to sterilize biological materials. This method is called Cold Sterilization because ionizing radiations produced relatively little heat in the material being irradiated. Thus it is possible to sterilize heat-sensitive substances by radiations and such techniques are being developed in the food and pharmaceutical industries (Jay, 1986; Adams and Moss, 1995; Chao et al., 2011).

Ultraviolet light has the bactericidal activity. Although the radiant energy of sunlight, is partly composed of UV light, most of the shorter wavelength of this are filtered by the earth's atmosphere is restricted. Many lamps are available which emit a high concentration of UV light in the most effective region. UV light has very little ability to penetrate matter. UV light is absorbed by many cellular materials but most significantly by the nucleic acids where it does the greatest damage. The absorption and subsequent reactions are predominantly in the pyrimidines of the nucleotide bases which result in killing of cells. Death of a population of UV-irradiated cells demonstrates log-linear kinetics (Jay, 1986; Adams and Moss, 1995; Chao et al., 2011).

Similar to thermal death and, in an analogous way, D values can be determined. These give the dose required to produce a tenfold reduction in surviving numbers where the dose, expressed in ergs, is the product of the intensity of the radiation and the time for which it is applied.

Determination of UV D values is not usually a straightforward affair since the incident radiation can be absorbed by other medium components and has very low penetration. Passage through $5 \mathrm{~cm}$ of clear water will reduce the intensity of UV radiation by two-thirds. This effect increases with the concentration of solutes and suspended material so that in milk $90 \%$ of the incident energy will be absorbed by a layer only $0.1 \mathrm{~mm}$ thick. This low 
penetrability limits application of UV radiation in the food industry to disinfection of air and surfaces (Jay, 1986; Adams and Moss, 1995; Chao et al., 2011).

Low-pressure mercury vapor discharge lamps are used: $80 \%$ of their UV emission is at a wavelength of $254 \mathrm{ohm}$ which has $85 \%$ of the biological activity of $260 \mathrm{om}$. Wavelengths below $200 \mathrm{~nm}$ are screened out by surrounding the lamp with an absorbent glass since these wavelengths are absorbed by oxygen in the air producing ozone which is harmful. The output of these lamps falls off over time and they need to be monitored regularly. Process water can be disinfected by UV; this avoids the risk of tainting sometimes associated with chlorination, although the treated water will not have the residual antimicrobial properties of chlorinated water. Process workers must also be protected from UV since the wavelengths used can cause burning of the skin and eye disorders. (Jay, 1986; Adams and Moss, 1995; Chao et al., 2011).

\subsection{Gamma-rays}

These are high energy radiations emitted from radioactive isotopes such as $60 \mathrm{C}$. they are similar to X-rays but of shorter wavelength. They have great penetration power and are lethal to all life including microbes. They are used for sterilization of materials of considerable thickness or volume. (Jay, 1986; Adams and Moss, 1995).

Microwave Radiation The microwave region of the e.m. spectrum occupies frequencies between $109 \mathrm{~Hz}$ up to $1012 \mathrm{~Hz}$ and so has relatively low quantum energy. Unlike the other forms of radiation, microwaves act indirectly on micro-organisms through the generation of heat. When a food containing water is placed in a microwave field, the dipolar water molecules align themselves with the field. As the field reverses its polarity 2 or $5 \times 109$ times each second, depending on the frequency used, the water molecules are continually oscillating. This kinetic energy is transmitted to neighbouring molecules leading to a rapid rise in temperature throughout the product. Microwaves are generated using a magnetron (Jay, 1986; Adams and Moss, 1995). The principal problem associated with the domestic use of microwaves is non-uniform heating of foods, due to the presence of cold spots in the oven, and the non-uniform dielectric properties of the food. These can lead to cold spots in some microwaved foods and concern over the risks associated with consumption of inadequately heated meals has led to more explicit instructions on microwaveable foods. These often specify a tempering period after heating to allow the temperature to equilibrate. (Jay, 1986; Adams and Moss, 1995; Prescott, 2011).

\subsection{Fresh marula fruit juice shelf life extension by hormonal application}

Most fruit first become ripened because of the release of a hormone within the fruit and the plant called ethylene $\left(\mathrm{H}_{2} \mathrm{C}=\mathrm{CH}_{2}\right)$. Ethylene causes the breakdown which in itself causes a production of enzymes that break down the structures of the fruit (e.g. amylase, pictenase).The ethylene gas also destroys the green pigment of the fruit chlorophyll. But for any fruit to become ripened there needs to be a high enough concentration of ethylene around the fruit to even begin to ripen. The process of the fruit spoiling is just the decomposition of the fruit itself. That is mostly caused by the two enzymes previously mentioned -amylase and pectinase. The role that these enzymes play are like biological scissors. The structure of plants are made out of carbohydrates - mostly starches (Jay, 1986; 
Adams and Moss, 1995; Allong et al., 2001; Prescott, 2011). The amylase acts on the starches, which are made of amylose, which is just a long chain of glucose molecule. And what the amylase does is it cuts the bonds of the starch chain, so then the glucose molecules are free; and now the fruit tastes sweet. The other enzyme pectinase does almost the exact same thing as amylase, it cuts away the bonds of the pectin molecule so now we have a bunch of pectinic acid, and now the fruit is soft enough to eat. Pectin is extremely important for fruits/plants because it hold the cells together. Fruits become discolored due to chemical reactions as well. Like previously stated before, ethylene destroys chlorophyll. When most fruits are produced, they all initially contain chlorophyll. Fruits then become ripened due to other chemicals within the fruit and as well as chemicals outside of the fruit (Jay, 1986; Adams and Moss, 1995; Prescott, 2011).

\subsection{Fresh marula fruit juice shelf life extension by appropriate hybrids or genetic manipulation}

Through selection hybrid trees that are short and easy to hand or machine pick can be produced. This would minimise contamination from the soil and improve the shelf life of the juice. This has been achieved in other plants where trees were bred to achieve heights where hand or machine picking was practiced with ease (Bergh and Whitsell, 1962).

\section{Laboratory work on some aspects of marula juice shelf life extension}

The aim of this study was to determine some aspects of physico-chemical conditions that could contribute to the shelf life extension of fresh marula juice.

Fruit juice is defined as the fermentable but unfermented juice pressed or squeezed from the fruit excluding the peel. Fresh juice has a very short life after extraction from the whole fruit, due to enzyme or microbial actions unless it is rapidly processed and/or preserved. Steps to achieve aseptic processing involve minimizing the presence of microorganism in the environment and on the product without compromising the organoleptic quality of the product. Since all fruit juices provide an excellent medium for microbiological activity it becomes imperative that high standards of hygiene are observed from the on set. To extract the juice the fruits were washed with chlorinated water and rolled on a clean hard surface and then pieced with a toothpick and the juice then squeezed out into clean containers. The single strength juice from different fruits was, pooled, filtered and subjected to the following treatments in 100ml containers: Blanching; Pasteurization; Sterilization; and Blanching /Pasteurization and then preserved with $0.1 \%$ Sodium Benzoate, one portion stored at $4^{\circ} \mathrm{C}$ and the other portion at $22^{\circ} \mathrm{C}$ for 8 weeks as a way of extending the shelf life. The following parameters were assessed, sugar content of the berry, acidity, and the $\mathrm{pH}$ at the green stage of the fruit to fully ripe yellow fruits to map out strategies for shelf life extension. There amount of Vitamin C (Ascorbic acid) was assessed for the following treatments Blanching; Pasteurization; Sterilization; and Blanching / Pasteurization as an indicator of stability. The ${ }^{\circ}$ Brix value and Browning index were determined. The sensory scores were determined to ensure that the treatments done do not result in an unpalatable product. Measurements of headspace were determined to evaluate its effect on the shelf life. Extending the life of fresh marula juice by altering its physico chemical properties were carried out in the laboratory as follows. 
1. Blanching in which the fruit juice was subjected to a temperature of $100^{\circ} \mathrm{C}$ for 3 minutes;

2. Pasteurization in which the fruit juice was subjected to a temperature of $82^{\circ} \mathrm{C}$ for 15 seconds;

3. Sterilization in which the fruit juice was subjected to a temperature of $100^{\circ} \mathrm{C}$ for 5 minutes;

4. Blanching and Pasteurization in which the fruit juice was subjected to both treatments as stated above. Each experiment had two replications to determine statistically significant differences between samples.

5. The juice from each treatment was preserved with $0.1 \%$ Sodium Benzoate, one portion stored at $4^{\circ} \mathrm{C}$ and the other portion at $22^{\circ} \mathrm{C}$ for 8 weeks.

Other Quality parameters were also assessed

6. Brix value; The oBrix was determined on a Riechart Abbe Refractometer. Distilled water was placed on the platform and the readings adjusted to zero then a drop of sample was placed on the platform and the total soluble solids (mostly sugars) value or ${ }^{\circ}$ Brix value were read and recorded.

7. Browning index; The browning index was determined. The brown pigments were extracted by diluting the juice 1:1 with $95 \%$ ethanol, filtering and measuring the absorbance at $420 \mathrm{~nm}$ on a Milton Roy spectrophotometer.

8. Total titratable acidity (TTA \%) For total titratable acidity $0.1 \mathrm{NaOH}$ was titrated against $1 \mathrm{ml}$ sample single strength juice containing a drop of $1 \%$ phenolphthalein indicator in $95 \%$ ethanol to a permanent end point pink colour at $\mathrm{pH} 8.1$.

9. Vitamin $\mathrm{C}$ content in $\mathrm{mg} / 100 \mathrm{~g}$ and vitamin $\mathrm{C}$ determination was done by taking $1 \mathrm{ml}$ of sample and titrating it with redox dye 2, 6-dichlorophenolindophenol (DCPIP) to a permanent pink colour and then concentration calculations were done. The juice of marula fruit is known to be rich in vitamin C (Hillman et al., 2008; Dlamini and Dube, 2008). Hillman et al., (2008), reported vitamin $C$ contents of marula clones ranging from 7 to $21 \mathrm{mg} / \mathrm{g}$ dry weight, amounts that were approximately 10 times higher than orange and pomegranate fruit juice. The high ascorbic acid content of marula makes it a cheap and accessible source of nutrients and antioxidants. The protection against disease provided by fruits and vegetables has been attributed to the various antioxidants contained in these foods. Because of its strong reducing properties, ascorbic acid acts a singlet oxygen quencher, thus reducing the damaging effect of free radicals which are implicated in the etiology of a number of diseases, including cancer and heart, vascular, and neurodegenerative diseases (Hillman et al., 2008).

10. Sensory score were monitored weekly for eight weeks Sensory score was done after previously documented methods. A trained 10-member panel holds the sample in the mouth, smell it and visualise it. The samples were coded with three-digit random numbers, placed in random order and served at $16^{\circ} \mathrm{C}$ in wine glasses. Unsalted crackers and water rinsing were utilized between each sample. Each panelist was asked to rate the samples for clarity, degree of browning, color, taste and flavor. A score sheet with vertical line scales for each rating was provided. Each scale was 10-cm long with anchor terms labeling each end. The top of the clarity scale was anchored with clear, and the bottom was anchored with extremely cloudy. The top of the browning scale was labeled with no browning, and the bottom was labeled with excessive browning. The tops of the color and flavor scales were anchored with highest value, and the bottoms were 
anchored with lowest value. The panelists were instructed to make a horizontal mark through the scale and write the corresponding sample number adjacent to the mark. The results were recorded on a scale of one to five. The sum of scores of each sample was divided by the number of panelist and the resulting average expressed as sensory score.

For microbial load the sample was diluted up to $10^{-4}$ in saline water and then plated on nutrient agar and colony forming units counted.

\section{Results}

The fruits ripen between February and April. The time from ripening onset to rotting of the fruit was $16 \pm 4$ days. Skin colour started to change on day 3 after abscission, and a completely yellow colour was obtained by day 12 . The sugar content of the berry increases rapidly, acidity (TTA\%) decreases, and the $\mathrm{pH}$ increases from 2.5 at the green stage of the fruit to 3.32 in fully ripe fruits. Berry skins lose chlorophyll and begin to develop characteristic yellow-gold colour. There was a significant decrease of Vitamin C (Ascorbic acid) due to processing in the order: Sterilize $>$ Blanch/pasteurise $>$ Pasteurise $>$ Blanch. At $22^{\circ} \mathrm{C}$ the first week shows the greatest decline in vitamin $\mathrm{C}$, which is followed by a period of improved stability. There is a decline in the ${ }^{\circ}$ Brix value with time in Blanched juice stored at $22^{\circ} \mathrm{C}$. At $4^{\circ} \mathrm{C}$ all treatments show minimal degradation in the ${ }^{\circ}$ Brix values and Browning index. The sensory score increases as the fruit ripens reaching its peak at ${ }^{\circ}$ Brix value of 13.5 , which corresponds to yellow colour stage of ripening. In response to various storage containers Browning index and vitamin $C$ content decreased in the order of liner $>$ plastic $>$ clear glass $>$ brown glass with time in juice stored at $22^{\circ} \mathrm{C}$. There was no significant change in sensory score of Sterilized and Blanched/Pasteurised juice stored at $4^{\circ}$. But at $22^{\circ} \mathrm{C}$ the decline in sensory score was rapid for all treatments. Measurements of headspace did not affect vitamin $\mathrm{C}$ content and browning index when the juice was stored at $4^{\circ} \mathrm{C}$ but at $22^{\circ} \mathrm{C}$ they did. Higher processing temperatures reduce microbial flora. Some fruits retained $80 \%$ of their vitamin $\mathrm{C}$ content after storage at $-18^{\circ} \mathrm{C}$ for two years.

\section{Discussion}

The pattern of fruit abscission differed among trees, but in most examined individual trees, $80 \%$ of the fruits abscised within two weeks which is in agreement with previous authors (Arthachinta, 2000). Ripening of abscised fruits is affected by storage temperatures. After 14 days of storage, fruits kept at $4^{\circ} \mathrm{C}$ remained green and firm, while those kept at $22^{\circ} \mathrm{C}$ developed a yellow color and could be squeezed for juice. As ripening progressed they developed a golden yellow color, higher juice content, and lower acidity as also noted for other fruits studied. The fruits began to develop brown spots on the skin one week after the on set of the deeper yellow colour. Similar observations have been made for other fruits studied (Huang and Liu, 2002; Brumell and Harpster, 2001; Mahayothee et al., 2002; Prasanna et al., 2007; Prescott, 2011). These results indicate that climacteric processes in marula start after abscission, which is in agreement with studies on other related fruits (Brumell and Harpster, 2001; Prasanna, et al., 2007; Prescott, 2011). Blanching as treatment of prolonging the shelf life has been used in the canning industries. The effect of this treatment was comparable with previous results from various fruits particularly reduction in vitamin 
C content (Brumell and Harpster, 2001; Prasanna, et al., 2007; Rico et al., 2007; Prescott, 2011). Sterilized marula juice remained in a stable state for extended periods but had the greatest loss of vitamin $C$ and sensory score recorded initially which is in agreement with previous studies on these attributes(Brumell and Harpster, 2001; Prasanna et al., 2007; Nassu et al., 2001; Prescott, 2011). ${ }^{\circ}$ Brix and TTA were not affected by sterilization. Pasteurization least affected the sensory score, the ${ }^{\circ}$ Brix, and Vitamin C. But the Browning index progressed rapidly under this treatment as previously recorded for other fruits(Brumell and Harpster, 2001; Prasanna et al., 2007; Prescott, 2011). Storage at $4^{\circ} \mathrm{C}$ showed the highest stability of the juice for all treatments however at $22^{\circ} \mathrm{C}$ the was a rapid decline of vitamin $\mathrm{C}$ and rapid increase in the browning index in the first two weeks which was followed by a more stable quality maintenance for six weeks of the study period. Similar observations have been noted in some fruits previously studied (Brumell and Harpster, 2001; Prasanna et al., 2007; Prescott, 2011). The drop in $\mathrm{pH}$ as fruits ripen has been similarly observed for other fruits (Brumell and Harpster, 2001; Prasanna et al., 2007; Prescott, 2011). In order to improve the shelf life of the non-alcoholic marula fruit juice, the appropriate headspace and the most suitable packaging materials should be established and then production of this juice can be embarked-on on a commercial scale. This will make the juice available to children. Thus a wider portion of the population will benefit from this nutritious resource. Efforts to improve on the shelf life of indigenous fruits have been successfully made in Malaysia and other developing countries (Brumell and Harpster, 2001; Prasanna et al., 2007; Prescott, 2011).

\section{Concluding remarks}

By modifying the physico-chemical conditions marula juice can have its shelf lie extended without compromising its organoleptic properties. The amounts of vitamin $\mathrm{C}$ are in agreement with previous studies and this vitamin has been used as measure of stability of fresh fruit juices a factor confirmed by this study. Sugar levels as measured by ${ }^{\circ}$ Brix and TTA and enzymatic browning are a function ripening and storage conditions and physicochemical conditions. Temperature in particular is critical for shelf life extension of fresh marula juice.

\section{Acknowledgements}

This work was funded by the NUST Research Board.

\section{References}

Adams, M.R. \& Moss, M.O. (1995). Food Microbiology Amazon UK $3^{\text {rd }}$ edition.

Aganga, A.A. \& Mosase, K.W. (2001). Tannin content, nutritive value and dry matter digestibility of Lonchocarpus capassa, Zizyphus mucronata, Sclerocarya birrea, Kirkia acuminata and Rhus lancea seeds. Animal Feed Science and Technology 91: 107 113.

Allong, R., Wickham, L.D. \& Mohammed, M. (2001). The effect of slicing on the rate of respiration ethylene production and ripening of mango fruit Journal of Food Quality 24: $13-20$.

Arthachinta, C. (2000) Mango research in Thailand. Proceeding of the Sixth International Symposium on Mango. International Society for Horticultural Science (ISHS), 33-35. 
Bergh, B.O. \& Whitsell, R. H. (1962). A possible dwarfing rootstock for avocados: California Avocado Society Yearbook 46: 55-62.

Blackstone, B. A. (1999). Principles and applications of modified atmosphere packaging of foods Second edition Aspen publishers

Brummell, D. A. \& Harpster, M.H. (2001). Cell wall metabolism in fruit softening and quality and its manipulation in transgenic plants. Plant Mol Biol. 47(1-2):311-40.

Chao Zhang, Bernhard Trierweiler, Wu Li, Peter Butz, Yong Xu, Corinna E. Rüfer, Yue Ma, \& Xiaoyan Zhao (2011). Comparison of thermal, ultraviolet-c, and high pressure treatments on quality parameters of watermelon juice Food Chemistry 126:254-260.

Cheikh Ndiaye, Shi-Ying Xu, \& Zhang Wang (2009). Steam blanching effect on polyphenoloxidase, peroxidase and colour of mango (Mangifera indica L.) slices Food Chemistry 113: 92-95.

Cullen P.J., Valdramidis, V.P., Tiwari, B.K., Patil, S., Bourke, P. \& O'Donnell, C.P. (2010). Ozone Processing for Food Preservation: An Overview on Fruit Juice Treatments, Ozone: Science \& Engineering, 32:3, 166-179.

Deliza R., Rosenthal, A. Abadio, F.B.D., Carlos, H., Silva, O. \& Castillo, C. (2005). Application of high pressure technology in the fruit juice processing: benefits perceived by consumers Journal of Food Engineering 67:241-246.

Dlamini, N.R. \& Dube, S. (2008). Studies on the physicochemical, nutritional and microbiological changes during the traditional preparation of Marula wine in Gwanda, Zimbabwe Nutrition and Food Science, Vol.38 No.1, pp. 61-69.

Emanuel, P.L., Shackleton, C.M., \& Baxter J.S. (2005). Modelling the sustainable harvest of Sclerocarya birrea subsp. caffra fruits in the South African lowveld. Forest Ecology and Management 214: 91-103.

Fox, F.W. \& Norwood, Y.M.E. (1982). Food from the veld. Edible wild plants of Southern Africa. Johannesburg and Cape Town: Delta 399.

Frank Albert Paine \& Heather Y. Paine (1992). A hand book of food packaging Blackie academic and professional an imprint Chapman and Hall London.

Hillman, Z., Mizrahi, Y. \& Beit-Yannai, E. (2008). Evaluation of valuable nutrients in selected genotypes of marula (Sclerocarya birrea ssp. caffra). Scientia Horticulturae 117 (2008) 321-328.

Liu, X.X. \& Huang, K.K. (2002). Textural and sensory properties of $\alpha$-Amylase treated poi stored at $4^{\circ} \mathrm{C}$. Journal of Food Processing and Preservation. 26: 35-37.

Indrawati Oey, Martina Lille, Ann Van Loey \& Marc Hendrickx, (2008). Effect of high pressure processing on colour, texture and flavour of fruit and vegetable-based food products: a review Trends in Food Science \& Technology 19:320-328.

Jay, J. M. (1986). Modern Food Microbiology. Van Nostrand Reinhold New York.

Mahayothee, B., Sybille, N., Mühlbauer, W. \& Reinhold, C. (2002). Effects of Postharvest Ripening Processes on the Quality of Dried Mango Slices Produced from Thai Mango Cultivars Nam Dokmai and Kaew. International Symposium Sustaining Food Security and Managing Natural Resources in Southeast Asia - Challenges for the 21st Century Chiang Mai, Thailand -January 8-11 :1-3.

Mdluli Kwanele M. (2005). Partial purification and characterisation of polyphenol oxidase and peroxidase from marula fruit (Sclerocarya birrea subsp. Caffra) Food Chemistry 92: 311-323. 
Michael, John Lewis \& Hepell, N.J. (2000). Continuous thermal processing of foods: Pasteurization and UHT sterilization Aspen publishers.

Mizrahi, Y. \& Nerd, A. (1996). New crops as a possible solution for the troubled Israeli export market. In: Janick J (Ed). Progress in new crops. ASHS Press, Alexandria, VA. 37-45.

Morga, N.S., Luste, A.O., Tunac, M.M., Balagot, A.H. \& Soriano, M.R. (1979). Physicochemical changes in Philippine Carabao mangoes during ripening. Food Chemistry. 15:225-234.

Nassu, R.T., Janiice, R., Lima, M.S.A., \& Moreira, D.S.F. (2001). Consumers' acceptance of fresh and combined methods for processed melons, mango, and cashew apple. Bras. Frutic, Jaboticabal - SP 23:551-554.

Nerd, A. \& Mizrahi, Y. (1993). Domestication and introduction of marula (Sclerocarya birrea subsp. Caffra) as a new crop for the Negev desert of Israel. In: Janick J and JE Simon (Eds). New crops. Wiley, New York. 496-499.

Ojewole, J.A.O., Mawoza, T., Chiwororo, W.D.H. \& Owira, P.M.O. (2010). Sclerocarya birrea (A. Rich) Hochst. ['Marula'] (Anacardiaceae): A Review of its Phytochemistry, Pharmacology and Toxicology and its Ethnomedicinal Uses. PHYTOTHERAPY RESEARCH 24: 633-639.

Palgrave, K.C. (1990). Trees of Southern Africa. Struik Publishers. Cape Town. 959.

Philip E. Nelson (2010). Principles of aseptic processing and packaging, 3rd edition Purdue University presses West Lafayette Indiana.

Prasanna, V., Prabha, T.N., \& Tharanathan R. N. (2007). Fruit ripening phenomena--an overview. Crit Rev Food Sci Nutr. 47(1):1-19.

Prescott Albert B. (2011). THE CHEMISTRY OF FRUIT-RIPENING. http://en.wikisource.org/wiki/popular science_monthly _volume_12/ february 1878 accessed 20 September 2011.

Rico, D., Martı́n-Diana, A.B., Barat J.M. \& Barry-Ryan, C. (2007). Extending and measuring the quality of fresh-cut fruit and vegetables: a review Trends in Food Science $\mathcal{E}$ Technology 18: 373-386.

Sampedro, F., Rodrigo, D. \& Hendrickx M. (2008). Inactivation kinetics of pectin methyl esterase under combined thermal-high pressure treatment in an orange juice-milk beverage Journal of Food Engineering 86:133-139.

Shackleton, S.E., Shackleton, C.M., Cunningham, A.B., Lombard, C., Sullivan, C.A. \& Netshiluvhi, T.R. (2002). A summary of knowledge on Sclerocarya birrea subsp. caffra with emphasis on its importance as a non-timber forest product in South and southern Africa. Part 1: Taxonomy, ecology, traditional uses and role in rural livelihoods. Southern African Forestry Journal, 194: 27 -41.

Van Wyk, B. \& Van Wyk P. (1997) Field guide to trees of South Africa. Struik Publishers. Cape Town. 536.

Van Wyk, B-E., van Oudtshoorn, B. \& Gericke, N. (2002). Medicinal plants of South Africa. 2nd edn. Briza: Pretoria 234-235.

Venter, F. \& Venter, J. (1996). Making the most of indigenous trees. Briza Publishers. Pretoria : 304.

Von Teichman, I. (1983). Notes on the distribution, morphology, importance and uses of the indigenous Anacardiaceae. The importance and uses of Sclerocaya birrea (the marula). Trees in South Africa; 35: 2-7. 


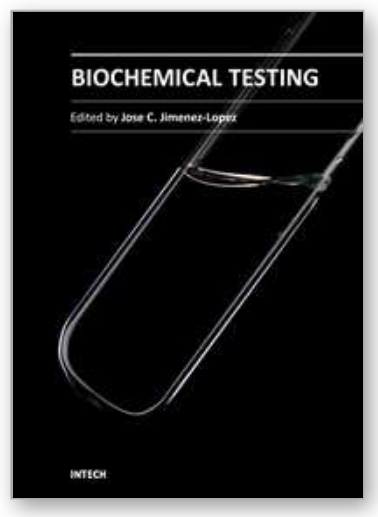

\author{
Biochemical Testing \\ Edited by Dr. Jose C. Jimenez-Lopez
}

ISBN 978-953-51-0249-6

Hard cover, 216 pages

Publisher InTech

Published online 07, March, 2012

Published in print edition March, 2012

Biochemical testing necessitates the determination of different parameters, and the identification of the main biological chemical compounds, by using molecular and biochemical tools. The purpose of this book is to introduce a variety of methods and tools to isolate and identify unknown bacteria through biochemical and molecular differences, based on characteristic gene sequences. Furthermore, molecular tools involving DNA sequencing, and biochemical tools based in enzymatic reactions and proteins reactivity, will serve to identify genetically modified organisms in agriculture, as well as for food preservation and healthcare, and improvement through natural products utilization, vaccination and prophylactic treatments, and drugs testing in medical trials.

\title{
How to reference
}

In order to correctly reference this scholarly work, feel free to copy and paste the following:

S. Dube, N.R. Dlamini, I. Shereni and T. Sibanda (2012). Extending the Shelf Life of Fresh Marula (Sclerocarya birrea) Juice by Altering Its Physico-Chemical Parameters, Biochemical Testing, Dr. Jose C. Jimenez-Lopez (Ed.), ISBN: 978-953-51-0249-6, InTech, Available from:

http://www.intechopen.com/books/biochemical-testing/title-extending-the-shelf-life-of-fresh-marulasclerocarya-birrea-juice-by-altering-its-physico-chem

\section{INTECH}

open science | open minds

\author{
InTech Europe \\ University Campus STeP Ri \\ Slavka Krautzeka 83/A \\ 51000 Rijeka, Croatia \\ Phone: +385 (51) 770447 \\ Fax: +385 (51) 686166 \\ www.intechopen.com
}

\author{
InTech China \\ Unit 405, Office Block, Hotel Equatorial Shanghai \\ No.65, Yan An Road (West), Shanghai, 200040, China \\ 中国上海市延安西路65号上海国际贵都大饭店办公楼405单元 \\ Phone: +86-21-62489820 \\ Fax: $+86-21-62489821$
}


(C) 2012 The Author(s). Licensee IntechOpen. This is an open access article distributed under the terms of the Creative Commons Attribution 3.0 License, which permits unrestricted use, distribution, and reproduction in any medium, provided the original work is properly cited. 